\title{
Investigation on self energized automated multi levels car parking system
}

\begin{abstract}
This work proposes a method to enhance the green power demands through providing an energy source which utilizes the kinetic green energy of the vehicles in multi-level car parking building, where vehicles are already climbing when the driver looking for space to park, and then climb down to go out the building with a kinetic energy due to ground gravity. A novel mechanism has been designed to generate electric power in each individual level from the car parking building, this individuality not only would generate more energy but also simplified the system and reduce the installation cost. The simulation result shows a significant energy value which could cover the demand of the parking place from the electricity, such as lighting, ventilation, barrier gate and CCTV.
\end{abstract}

Keyword: DC generator; Electrical energy calculation; Energy management system; Energy storage systems; Kinetic energy of a freely falling body; Left mechanism; Parking automation; Vehicle parking system 